\title{
Modified technique of intralenticular aspiration for anteriorly dislocated lens with iridocorneal touch in buphthalmic eyes
}

\author{
Sudarshan Khokhar, Mousumi Banerjee 두 , Avilasha Mohapatra
}

Dr R.P. Centre for Ophthalmic Sciences, All India Institute of Medical Sciences, New Delhi, Delhi, India

\section{Correspondence to} Dr Mousumi Banerjee; banerjeemou12@gmail.com

Accepted 14 July 2021

\section{DESCRIPTION}

Spontaneous anterior dislocation of crystalline lens in paediatric patients is an ophthalmic emergency and warrants immediate surgical intervention to prevent long-term ocular complications such as glaucoma and corneal decompensation. ${ }^{1}$ Traumatic dislocation accounts for majority of the cases. ${ }^{2}$ Tearing of the zonules in buphthalmos can also lead to secondary lens luxation. ${ }^{3}$

Intralenticular aspiration technique is one of the most common techniques implemented by surgeons worldwide to manage such challenging cases. ${ }^{14}$

Herein, we describe a modified technique of intralenticular aspiration to manage bilateral anteriorly dislocated lens with iridocorneal touch and corneal decompensation in buphthalmic eyes.

Surgery was performed under general anaesthesia under explained poor visual prognosis, and
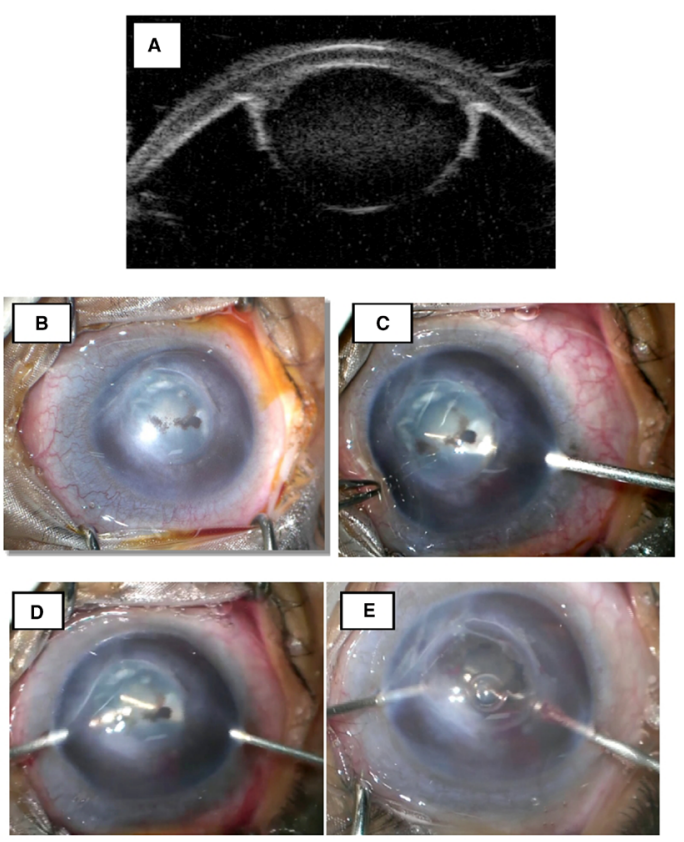

Figure 1 Ultrasound biomicroscopy imaging revealed total iridocorneal and corneolenticular touch with intumescent lens (A). Clinical photograph of the anteriorly dislocated lens with iris bombe and corneal oedema (B). Stab incision with microvitreoretinal blade through clear cornea passing through full thickness of iris and posterior capsule of lens (C). Intralenticular aspiration with vitrectomy cutter and irrigation cannula in I-A cut mode (D). Removal of the lens capsule with vitrectomy cutter in cut I-A mode (E).

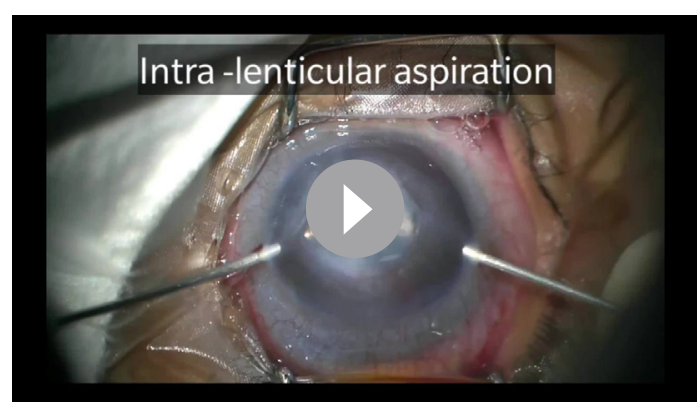

Video 1 Depiction of the surgical steps of our modified technique of intralenticular aspiration with vitrectomy cutter and irrigation cannula in irrigation-aspiration cut mode.

preoperative ultrasound biomicroscopy (UBM) was performed on the operating table for a detailed structural evaluation of the anterior segment. UBM revealed total iridocorneal and corneolenticular touch with intumescent lens (figure 1A). All the surgeries were performed by a single surgeon (SK) sitting superiorly at the 12 o'clock position. Two stab incisions were made at 10 o'clock and 2 o'clock positions with microvitreoretinal (MVR) blade in the clear cornea just anterior to the limbal vascular arcade. The tip of the blade was further inserted horizontally through the full thickness of the adjacent iris with a stab incision through the posterior capsule of the lens horizontally (figure 1B,C). This was followed by intralenticular aspiration of the lens with a $25 \mathrm{G}$ vitrectomy cutter through one incision in the posterior capsule and $27 \mathrm{G}$ irrigation cannula through the other, holding the capsular bag-lens complex in place (figure 1D). Lens aspiration was performed in irrigation-aspiration (I-A) cut mode on a Centurion Vision system based on active fluidics technology, keeping vacuum at $400 \mathrm{~mm} \mathrm{Hg}$, aspiration flow rate at $25 \mathrm{cc} / \mathrm{min}$, cut rate at $100 \mathrm{cpm}$ and intraocular pressure (IOP) at $40 \mathrm{~mm} \mathrm{Hg}$ equivalent to a bottle height of $54 \mathrm{~cm}$ water. A capsular bag was then compromised with the cutter in cut I-A mode, keeping cut rate at 4000 $\mathrm{cpm}$, vacuum at $250 \mathrm{~mm} \mathrm{Hg}$ and aspiration flow rate at $20 \mathrm{cc} / \mathrm{min}$. Limited anterior vitrectomy was performed in cut I-A mode to ensure that there was no remnant of vitreous strands in the anterior chamber (figure 1E). At the end of the surgery, anterior chamber was formed with balanced salt solution, and stromal hydration of the ports was performed. Two surgical peripheral iridotomies (PIs) were already made $180^{\circ}$ apart at the beginning 
of the surgery when the MVR blade was inserted through the full thickness of the iris to reach the posterior lens capsule.

Video 1 depicts the surgical steps of our technique.

In our case, we did not have any space to manipulate in the anterior chamber and our technique prevented further damage to the corneal endothelium. Additionally, a single instrument was

\section{Patient's perspective}

I was happy with the postoperative outcome of my child and she could see better than before due to early intervention.

\section{Learning points}

- Spontaneous anterior dislocation of crystalline lens patients is an ophthalmic emergency and warrants immediate surgical intervention to prevent long-term ocular complications such as glaucoma and corneal decompensation.

- Preoperative ultrasound biomicroscopy imaging is a simple, less expensive imaging modality which could pick up subtle changes in the anterior segment easily, enabling better surgical planning.

- This technique of intralenticular lens aspiration through the limbal route could be performed in patients requiring urgent surgical intervention with nil (Von Herick zero) anterior chamber and sclera thinning. It precludes the need for additional PI and also prevents manipulation in the anterior chamber, hence reducing the risk of further damage to the corneal endothelium. used (vitrectomy cutter) in two different modes for performing lens aspiration followed by removal of the capsular bag, thus preventing the need for change of instruments, making the procedure simple and easier. We did not encounter any posterior segment complication or lens drop while performing controlled lens aspiration in I-A cut mode with the aforementioned settings.

To conclude, our technique of intralenticular lens aspiration through the limbal route is a safe and simple technique which could be performed in patients requiring urgent surgical intervention with nil (Von Herick zero) anterior chamber and sclera thinning precluding lensectomy through the pars plana route.

Contributors SK performed the surgery. MB and AM worked up the case and prepared the manuscript. SK edited the final manuscript.

Funding The authors have not declared a specific grant for this research from any funding agency in the public, commercial or not-for-profit sectors.

Competing interests None declared.

Patient consent for publication Parental/guardian consent obtained.

Provenance and peer review Not commissioned; externally peer reviewed.

ORCID iD

Mousumi Banerjee http://orcid.org/0000-0003-4346-246X

\section{REFERENCES}

1 Vasavada AR, Praveen MR, Desai C. Management of bilateral anterior dislocation of a lens in a child with Marfan's syndrome. J Cataract Refract Surg 2003;29:609-13.

2 Choi D-Y, Kim J-G, Song B-J. Surgical management of crystalline lens dislocation into the anterior chamber with corneal touch and secondary glaucoma. J Cataract Refract Surg 2004;30:718-21.

3 Miller PE. Slatter's fundamentals of veterinary ophthalmology. 4 edn, 2008: 230-40.

4 Mukhopadhyaya U, Chakraborti C, Mondal A, et al. Spontaneous dislocation of a crystalline lens to the anterior chamber with pupillary block glaucoma in Noonan syndrome: a case report. Pan Afr Med J 2014;17:135.

Copyright 2021 BMJ Publishing Group. All rights reserved. For permission to reuse any of this content visit

https://www.bmj.com/company/products-services/rights-and-licensing/permissions/

BMJ Case Report Fellows may re-use this article for personal use and teaching without any further permission.

Become a Fellow of BMJ Case Reports today and you can:

- Submit as many cases as you like

- Enjoy fast sympathetic peer review and rapid publication of accepted articles

- Access all the published articles

- Re-use any of the published material for personal use and teaching without further permission

Customer Service

If you have any further queries about your subscription, please contact our customer services team on +44 (0) 2071111105 or via email at support@bmj.com.

Visit casereports.bmj.com for more articles like this and to become a Fellow 